SCIENTIFIC LETTER

\title{
Mitral balloon valvotomy and left atrial thrombus
}

\author{
T R D Shaw, D B Northridge, N Sutaria
}

Heart 2005;91:1088-1089. doi: 10.1136/hrt.2004.034959

$T^{1}$ he presence of thrombus in the left atrium (LA) is an important factor in the selection of cases for percutaneous mitral balloon valvotomy (MBV). This is because of the danger of embolisation caused by manipulation of guidewires and balloon catheters. The American College of Cardiology/American Heart Association recommendations for $\mathrm{MBV}^{1}$ emphasise absence of LA thrombus. Transoesophageal echocardiography (TOE) has a high sensitivity for detection of cavity and appendage LA thrombi (93-100\%) and is normally carried out before MBV. We report our experience of MBV in patients who had an LA thrombus at initial TOE.

\section{METHODS}

Of 313 patients admitted for MBV, TOE was tolerated in 310. The characteristics of these patients are shown in table 1. Each patient had a two dimensional Doppler transthoracic echocardiogram (TTE) and TOE on the morning of the planned MBV. Warfarin treatment had been stopped at home three days earlier. Subcutaneous heparin was not given. MBV was by the Inoue technique. ${ }^{2}$ Intravenous heparin (100 units per kg body weight) was given after transseptal puncture.

\section{RESULTS}

LA thrombus was found in 41 (13\%) of the 310 patients. In those with thrombus $98 \%$ had received warfarin treatment. Overall $95 \%$ of patients had been receiving warfarin treatment. The characteristics of the patients who did, and did not, have LA thrombus are compared in table 1 . The patients with thrombus were significantly older, had atrial fibrillation more often, and had more severe mitral stenosis with a lower cardiac output and higher right ventricular systolic pressure. They also had a significantly larger LA echo-dimension. Thrombus was significantly more likely in those patients considered unsuitable for cardiac surgery. On multiple regression analysis the independent predictors of LA thrombus were severity of mitral stenosis $(\mathrm{p}<0.001)$ and presence of atrial fibrillation $(\mathrm{p}<0.05)$.

Five $(7.9 \%)$ of the 63 patients who had had previous surgical valvotomy had an LA thrombus of any type, while in the 247 patients without previous valvotomy, thrombus was detected in $36(14.6 \%)$. The corresponding incidence for LA appendage thrombus was $3.2 \%$ and $10.5 \%$, respectively. These differences did not reach significance $(p=0.06)$. Patients with mitral reflux also had a non-significant trend to less frequent LA thrombus.

Thrombus distribution was of four types: thrombus adjacent to the atrial septum (two patients); thrombus protruding from the LA wall into the atrial cavity (five patients); smooth laminar thrombus adherent to the LA wall (six patients); and thrombus only at the LA appendage (28 patients).

Of the two patients with thrombus at the inter-atrial septum one had a three month period of intensified warfarin treatment. The other patient, too ill to leave hospital, had a 10 day period of intravenous heparin. Neither showed any resolution of the thrombus on repeat TOE. Both were referred for cardiac surgery although they were high risk surgical
Table 1 Characteristics of patients with and without LA thrombus at initial TOE before planned MBV

\begin{tabular}{|c|c|c|c|}
\hline & $\begin{array}{l}\text { Patients with no } \\
\text { LA thrombus at } \\
\text { TOE }\end{array}$ & $\begin{array}{l}\text { Patients with } \\
\text { LA thrombus } \\
\text { at TOE }\end{array}$ & p Value \\
\hline Number of patients & 269 & 41 & \\
\hline Age (years) & $60.2(12.7)$ & $64.9(11.1)$ & $<0.05$ \\
\hline Female & $217(81 \%)$ & $31(76 \%)$ & \\
\hline Previous rheumatic fever & $102(38 \%)$ & $13(32 \%)$ & NS \\
\hline Previous surgical valvotomy & y $58(22 \%)$ & $5(12 \%)$ & NS \\
\hline Atrial fibrillation & $189(70 \%)$ & $38(93 \%)$ & $<0.01$ \\
\hline Warfarin therapy & 253 (94\%) & 40 (98\%) & \\
\hline Echo score & $6.3(2.7)$ & $7.0(3.0)$ & NS \\
\hline LA echo-dimension & $5.34(1.17)$ & $5.71(0.93)$ & $<0.05$ \\
\hline Parsonnet score & $14.5(8.7)$ & $17.1(8.7)$ & NS \\
\hline $\begin{array}{l}\text { Patients unsuitable for } \\
\text { cardiac surgery }\end{array}$ & $52(19 \%)$ & $14(34 \%)$ & $<0.05$ \\
\hline $\begin{array}{l}\text { Mitral reflux on LV } \\
\text { angiogram }\end{array}$ & $89(33 \%)$ & $10(24 \%)$ & NS \\
\hline LV impairment & $20(7 \%)$ & $4(10 \%)$ & NS \\
\hline $\begin{array}{l}\text { RV systolic pressure } \\
\text { (mm Hg) }\end{array}$ & $50.4(18.0)$ & $57.7(17.6)$ & $<0.05$ \\
\hline Mean LA pressure $(\mathrm{mm} \mathrm{Hg})$ & ) $25.2(7.1)$ & $26.7(5.9)$ & NS \\
\hline Valve gradient $(\mathrm{mm} \mathrm{Hg})$ & $12.0(5.1)$ & $11.6(3.7)$ & NS \\
\hline Cardiac output (l/min) & $3.67(0.94)$ & $3.10(0.72)$ & $<0.001$ \\
\hline Valve area $\left(\mathrm{cm}^{2}\right)$ & $0.97(0.30)$ & $0.78(0.23)$ & $<0.001$ \\
\hline
\end{tabular}

Data are represented as mean (SD).

LA, left atrium; LV, left ventricle; RV, right ventricle, TOE,

transoesophageal echocardiography.

candidates and both died in the perioperative period. In both patients the LA thrombus had been seen on TTE.

In five patients the thrombus protruded from the LA wall into the cavity. None of these patients proceeded to same day MBV. In one patient TOE showed extensive subvalvar change and this patient was referred for valve replacement. Four patients had a three month period of intensive anticoagulation (international normalised ratio (INR) 3.5-4.5). In two patients thrombus resolved completely and they underwent MBV without complication. In the other two patients the thrombus showed partial resolution. A 75 year old woman had extensive protuberant LA wall thrombus on initial TOE. After intensive anticoagulation, repeat TOE suggested that the thrombus had become organised, adherent, and reduced in volume, although still protuberant. However, at MBV a dense hemiplegia developed because of a thrombus embolised to the right carotid artery. A 46 year old patient showed reduced, but still protuberant, thrombus at repeat TOE after intensive anticoagulation. After a further four months of intensive anticoagulation, TOE showed the thrombus to have become smooth, laminar, and nonprotuberant. This patient had MBV without complication. In two of these five patients thrombus was identified on TTE.

Abbreviations: LA, left atrium; MBV, mitral balloon valvotomy; $T O E$, transoesophageal echocardiography; TE, transthoracic echocardiogram 
Six patients had a smooth surface, laminar thrombus attached to the LA wall. Each had MBV immediately after their TOE. One patient had a transient episode of diplopia resolving within two days. No thrombus was detected in any of these six patients at TTE.

In 28 patients there was thrombus only at the LA appendage. The thrombus was entirely within the appendage in 21 patients. Each of these 21 patients proceeded to same day MBV. None had evidence of embolism. In seven patients the thrombus protruded just beyond the mouth of the appendage or had a mobile portion lying at the mouth. One of these seven patients was found at TOE to have mitral valve morphology unsuitable for MBV and this patient was referred for valve replacement. The remaining six all had a further period of intensive anticoagulation for three months. There was complete clearing of the thrombus in three patients while the three remaining patients showed partial resolution, with the thrombus then lying entirely within the appendage. All six patients had MBV immediately after their repeat TOE and none had embolism. TTE had not detected the thrombus in any of these 28 patients.

\section{DISCUSSION}

We found that LA thrombus in patients with mitral stenosis is not uncommon (13\%), despite warfarin treatment. However, further intensive anticoagulation therapy can resolve the thrombus in some, but not all, patients. ${ }^{34}$ Many of the patients in this series were elderly with co-morbidity which made surgical treatment contraindicated or high risk. In those with a pressing need for MBV, valve dilatation can be safely achieved if the thrombus is within the LA appendage or laminar wall thrombus, but should always be avoided in those with thrombus at the atrial septum, protruding in the LA cavity, or when mobile at the appendage mouth. LA thrombus tended to be less frequent in those with a previous surgical valvotomy, but resection of the appendage is said to reduce atrial natriuretic factor response and LA compliance. ${ }^{5}$ Embolism, caused by valve fragments, can occur $(0.8 \%$ in our series $)$ at MBV in those without LA thrombus.

\section{Authors' affiliations}

T R D Shaw, D B Northridge, N Sutaria, Department of Cardiology, Western General Hospital, Edinburgh, UK

Correspondence to: Dr Thomas R D Shaw, Department of Cardiology, Western General Hospital, Crewe Road South, Edinburgh EH4 2XU, UK ; trd.shaw@blueyonder.co.uk

Accepted 5 March 2004

\section{REFERENCES}

1 Bonow RO, Carabello B, de Leon AC, et al. ACC/AHA guidelines for the management of patients with valvular heart disease: executive summary. $A$ report of the American College of Cardiology/American Heart Association task force on practice guidelines (committee on management of patients with valvular heart disease). Circulation 1998;98:1949-84.

2 Inoue K. Percutaneous transvenous mitral commissurotomy using the Inoue balloon. Eur Heart J 1991; 12(suppl B):99-108.

3 Kang DH, Song JK, Chae JK, et al. Comparison of outcomes of percutaneous mitral valvuloplasty versus mitral valve replacement after resolution of left atrial appendage thrombi by warfarin therapy. Am J Cardiol 1998;81:97-100.
4 Jaber WA, Prior DL, Thamilarasan M, et al. Efficacy of anticoagulation in resolving left atrial and left atrial appendage thrombi: a transesophageal echocardiographic study. Am Heart J 2000;140:150-6.

5 Al-Saady NM, Obel OA, Camm J. Left atrial appendage: structure, function and the role in thromboembolism. Heart 1999;82:547-55.

\section{WEB TOP 10}

www.heartjinl.com

These articles scored the most hits on Heart's website during May 2005

1 Assessment of diastolic function: what the general cardiologist needs to know

PM Mottram, TH Marwick

May 2005;91:681-95. (Education in Heart)

2 The changing face of acute myocardial infarction

N Danchin

June 2005;91:705-6. (Editorial)

3 Prediction and prevention of sudden cardiac death in heart failure

RE Lane, MR Cowie, AWC Chow

May 2005;91:674-80. (Education in Heart)

4 The Fontan circulation

M Gewillig

June 2005;91:839-46. (Education in Heart)

5 Stem cell therapy for myocardial repair

PL Weissberg, A Qasim

June 2005;91:839-46. (Education in Heart)

6 Prophylaxis of infective endocarditis: French recommendations 2002

N Danchin, X Duval, C Leport

June 2005;91:715-8.

7 Xanthine oxidase inhibition for chronic heart failure: is allopurinol the next therapeutic advance in heart failure? W Doehner, SD Anker

June 2005;91:707-9. (Editorial)

8 Endothelin antagonism in pulmonary hypertension, heart failure, and beyond

$T$ Attinà, $R$ Camidge, DE Newby, DJ Webb

June 2005;91:825-31. (Education in Heart)

9 Late opening of the infarct related artery: an open or shut case?

ZR Yousef, MS Marber, SR Redwood

June 2005;91:825-31. (Editorial)

10 Non-invasive multislice CT coronary imaging

NR Mollet, F Cademartiri, PJ de Feyter

March 2005;91:401-7. (Education in Heart)

Visit the Heart website for hyperlinks to these articles, by clicking on "Top 10 papers"

www.heartjnl.com 